successful than linoleic acid has yet to be proved.

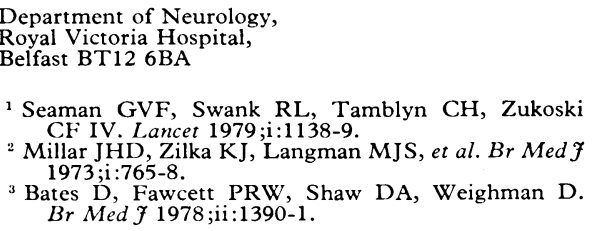

\section{Retrospective versus prospective} controls in clinical trials

SIR,-It has happened again. Many a time now, in my relatively short medical career, I have accepted as gospel truth medical knowledge without personally examining its foundations, only to find some time later that those foundations are almost non-existing. Examples include tonsillectomy, anticoagulant therapy for infarction, and cleansing the skin with alcohol before venepuncture. The most recent example was the attack on the holiness of prospective trials launched by $\mathrm{Dr}$ Lawrence Cranberg (17 November, p 1265). His article fills one's heart with fear, for no longer will one be able to stand up at Grand Rounds and put down some bright young whippersnapper: "Yes, but were those findings confirmed in a prospective trial ?"

In spite of such disadvantages, $\mathrm{Dr}$ Cranberg's article has one great advantage: it leads us to examine the postulates on which clinical trials are based. In physics and chemistry there is no need for concurrent controls, for the variables are few and well known. Experiments are designed in serial fashion, altering one variable at a time. A careful record of the critical variables is kept and the experiment can be repeated time and time again, with identical results. In biology, however, we not only have a greatly increased number of variables, we also understand them less well. Indeed, sometimes we are not aware of variables that may effect the outcome of the experiment. This problem has been circumvented by the process of matching experimental preparations and then introducing a known controllable variable (administration of a chemical, the making of a lesion, etc) to one of the matching pair only, usually in a randomised fashion. The effect of the introduced variable is then determined by observing any difference between the pairs that did not exist initially. It is necessary only to match for those variables that might be affected by the experimental process. Thus sex, weight, age, concentration of certain metabolites, and the presence and severity of certain characteristics such as symptoms and signs of disease are among the more important variables. Duration of a disease may be important, but the point in time at which a variable is tested rarely is (provided ambient temperatures, etc, are treated as different variables). Yet the only advantage of the use of concurrent controls is to be able to say that the two experiments were done at the same point in time in the life of the universe. Other apparent advantages, such as ease of comparison for sameness, are important only in experiments where the variables are improperly recorded. Generally, the result of such work is as sloppy as the record keeping. Finally, it has been suggested by some reviewers of grant applications-not, of course, any associated with agencies to which I apply for funds-that a temptation exists in retrospective trials to select the controls and experimental subjects on the basis of the expected or desired outcome. To those individuals I would say: "The null hypothesis states that there is no difference in the inherent honesty of researchers using retrospective and concurrent controls." Until the latter is disproved in a prospective, doubleblind crossover trial, I shall feel justified in using retrospective or concurrent controls as dictated by the variables of the experimental situation.

In conclusion, thank you, Dr Cranberg.

Gerald TeVaARWERK

Department of Medicine,

University of Western Ontario,

St Joseph's Hospital,

London, Ontario,

\section{Rehabilitation}

SIR,-May I take up some points from Dr D H Bossingham's letter (8 December, p 1508)?

It is certainly the responsibility of doctors, at both primary and secondary care level, to think about any necessary stages in rehabilitation that their patients might need during recovery, and to direct their patients in the desired direction and to the appropriate agencies for any help needed after (or during) clinical treatment. Unfortunately, rehabilitation is considered to be a "soft" subject and, perhaps partly for this reason, often induces an apparent occupational deafness in harassed clinicians.

If the subject is to become more scientific, thought and attention must be given to developing valid measures of outcome and evaluating different rehabilitation procedures. The recently founded Society of Research in Rehabilitation provides a forum for many disciplines (not only medicine but others including the remedial professions) to look critically at work that is being done not only in medical rehabilitation but in other fields, such as those of occupational assessment and employment rehabilitation.

Dr Bossingham points out that many doctors do not make use of the Manpower Service Commission's employment rehabilitation centres to help their patients return to work, if such an assessment is needed. While the employment rehabilitation centre does not provide training, a skilled occupational assessment can be given by a team which includes not only medical and nursing advice but also that of occupational psychologists and skilled workshop supervisors. Such an assessment may be followed by a placement directly into suitable work or possibly by training.

The number of referrals of patients to these centres from doctors has steadily declined over the last few years. There are many possible reasons for this, and to try to counteract this trend the Employment Medical Advisory Service (EMAS), which now provides medical and nursing services for 25 of the 27 employment rehabilitation centres, has recently agreed with the Employment Service Division (which manages the centres) the introduction of an additional method of direct medical referral of patients to the employment medical adviser at the centre. This referral could come from doctors working at either primary or secondary health care level.
I would like to draw your readers' attention to the further information about this new facility on p 193

\section{Felicity C EDWARDS}

Employment Medical Advisory Service, Health and Safety Executive,

\section{Drug names that look or sound alike}

SIR,-In the issue of 17 November (p 1297), Drs $R$ N Palmer and F V Simpson cite instances of similar sounding drugs causing confusion. It is thus ironic that on the following page (1298) "Minerva" is confused by one of the very drug pairs listed by Dr $\mathrm{H}$ McNulty and Mr P Spurr (6 October, p 836). In the letter she quotes ${ }^{1}$ Montello and her colleagues at the Children's Hospital of Philadelphia used clotrimazole and not co-trimoxazole to treat their patient's oral thrush. Dr W T Houlsby (p 1297) should note that these are the approved names-surely an unnecessary confusion but one which may lessen if trimethoprim alone replaces co-trimoxazole in common use.

An oral preparation of clotrimazole appears not to be available in this country ${ }^{2}{ }^{3}$ but there is a suitable formulation of miconazole. Dakatrin Oral Gel (Janssen Pharmaceutical Ltd) is designed to persist in the mouth and might thus be a candidate for prescription "by thumb."

NeIl C Fraser

Royal Hospital for Sick Children,

${ }^{1}$ Montello JM, Darby MH, Faubel K, August CS. New Engl f Med 1979;301:1005

Data Sheet Compendium 1979-80. London: Pharmind Publications. Ltd.

Publishing Ltd.

\section{Iatrogenic collapse}

SIR,-I would like through your columns to discuss points brought up by $\mathrm{Dr} \mathrm{M} J$ Boscoe (24 November, $p$ 1367). A complication of profound respiratory depression is serious indeed, but I felt somewhat reassured after reading the references quoted in his letter.

In the fifth edition of The Pharmaceutical Basis of Therapeutics ${ }^{1}$ respiratory depression is mentioned as a complication of Pamergan (pethidine hydrochloride $100 \mathrm{mg}$, promethazine hydrochloride $25 \mathrm{mg}$, and atropine sulphate $0.6 \mathrm{mg}$ ), but no statistics are given. In a large series ${ }^{2}$ respiratory depression of short duration occurred in two patients out of 774 receiving the drug parenterally. This covers 10320 doses of the drug, an incidence of $0.02 \%$. One of these two patients was suffering from advanced carcinoma of the oesophagus and the second was markedly debilitated with generalised arteriosclerosis.

Comparing seven analgesic drugs, Prescott et $a l^{3}$ showed that all of them had caused some depression of respiration, a fact that is of great importance in obstetric practice owing to possible depresssant effects on the respiration of the newborn. He quotes that, of the more established drugs, pethidine is the most useful obstetric analgesic. Of the eight medical students he investigated, respiratory depression was shown by asking volunteers to breathe a gas mixture containing $0.5 \%$ carbon dioxide in oxygen, the analgesics being injected intramuscularly after an initial record had been taken. No subject suffered profound respiratory depression. 
The makers of Pamergan, May and Baker, have had a total of five adverse reports on this drug between 1963 and 1976. Three of these involved neonates, one was a report of laryngitis associated with Pamergan use, and the fifth was a case of apnoea. I was unable to obtain the reference referring to this incident. No case was fatal.

The Committee on the Safety of Medicines have had four reports concerning Pamergan. None of them were really relevant to respiratory depression. The poisons unit at New Cross Hospital checked its case records and could find no incident of acute poisoning due to Pamergan.

To summarise, I have been unable to find figures comparing the relative frequency of vasovagal faints during the insertion of an intrauterine contraceptive device and profound respiratory depression following parenteral Pamergan or pethidine. I agree that the former are rare, but, from the evidence (or rather the lack of it) that I have been able to find so far, profound respiratory depression seems to be even more rare. It is certainly important for anyone using Pamergan AP100/ 25 to have nalorphine ampoules available should it be necessary to use this narcotic antagonist to counteract respiratory depression.

London SW3 6PX

K M Huntington

1 Goodman LS, Gilman A, eds. The pharmaceutical basis of therapeutics, 5 th ed. New York: Macmillan, basis of therd
$1975: 266$

Batterman RC. Arch Intern Med 1943;71 :345-56.

Prescott F, Ransom SG, Thorp RH, Wilson A. Lancet $1949 ; \mathrm{i}: 340-4$

\section{Placement of subnormal offenders}

SIR,-Contrary to what Dr D A Spencer writes (8 December, p 1511), may I reassure readers that it remains the practice of this prison hospital to seek via the RHA consultant opinion on all court report cases which clinically appear to merit hospital admission, with a view to submitting positive medical recommendations to courts.

Regrettably we are experiencing considerable difficulty in obtaining beds both for subnormal and for ill defendants.

DAPHNE SASIENI

HM Prison,

\section{False friends}

SIR,-Peter Newmark's reference to faux amis or misleading cognate words (1 December, p 1405) opens up a subject that always strikes a chord with those colleagues struggling with their French, though one example he did not give is one he would almost certainly meet if pitchforked into a French family with academic connections: passer un examen is not to pass an examination in the sense we understand it but only to sit for it, and serious French examinations being what they are the chances of success may be slim. Congratulations should thus be withheld at this stage Succéder - or réussir à would be the welcome words and occasion for rejoicing.

English seems to need fewer words than French, this being my own simple explanation why the BBC news in French is run through at literally breathless speed, even with some Franglais words to help matters along. None the less there can be both delicacy and aptness in some French words. An old lady may, for instance, be une dame d'un certain age, while "taking off" in the aeroplane sense is décollage, colle being glue, a feeling airline pilots know only too well-in the old days pilot experience was in terms of millions of miles flown whereas nowadays it is the number of times he gets off the ground without incident.

ROBERT CUTLER

Surbiton, Surrey KT6 6PR

\section{Sodium valproate and platelet counts}

SIR,-The report of the presence of platelet antibodies in the blood of patients on sodium valproate by $\operatorname{Dr} R M$ Sandler and others (8 December, $p$ 1476) possibly explains the finding of reduced platelet counts without obvious thrombocytopenia in similar patients on sodium valproate. Following reports of occasional thrumbocytopenia during sodium valproate therapy, platelet counts were included in 1469 full blood counts made between January 1978 and May 1979 on blood samples received from hospitals dealing entirely with epileptic and non-epileptic mentally handicapped patients.

While the mean platelet counts for nonepileptics and epileptics treated with anticonvulsants other than sodium valproate were not significantly different $(p>0.05)$, the mean platelet counts from epileptics not on sodium valproate and from epileptics on sodium valproate were significantly different $(p<0.02>$ 0.01 ). We have no explanation for a second finding in our investigation-namely, that the second platelet counts in our patients were significantly higher than the first counts. It is tempting to suggest that our request for care during venepuncture and mixing of blood samples may have had some influence. If this is true, then our new Coulter Supe Plus Counter, which automatically counts and sizes platelets in addition to the other measurements, may give an answer to this problem.

\section{R L EASTHAM} J JANCAR

Department of Pathology, Frenchay Hospital,
Bristol BS16 1LE

\section{Long-term outcome after severe head injury}

SIR,-The report by $\mathrm{Mr}$ Walpole Lewin and others (15 December, p 1533) on the longterm outcome after severe head injury they observed in 291 survivors out of 479 patients with prolonged amnesia or unconsciousness lasting a week or more is of considerable interest. Their results closely agree with our observations of severe head injury among patients in Sweden, details of which we hope to publish later. Out of 295 consecutive patients admitted to the intensive care unit in Sundsvall, Sweden, between 1961 and 1977 all with severe head injuries (criteria for admission unconsciousness or decerebration lasting more than half an hour), $40 \%$ died, although age was a critical factor.

Of the 117 Swedish survivors who were subsequently traced, $14 \%$ were in permanent institutional care or in receipt of a permanent disability pension. In the Oxford series $12 \%$ were classified as severely disabled or worse. In the Swedish series $44 \%$ of the follow-up group (25\% of admissions) had no residual symptoms; in the Oxford group $20 \%$ only had no residual disability. The similarity of results would suggest that, given appropriate medical and nursing care, the probable outcome can be predicted within an hour of injury rather than after a week, but that if unconsciousness becomes prolonged there is an increased likelihood that the patient will have a residual neurophysical disability, if he survives-in the Swedish series $64 \%$ of the 121 patients who were unconscious the day after injury died.

P J TOMLIN

University Department of Anaesthetics, Queen Elizabeth Hospital

\section{An academy of medicine}

SIR,-Having written in support of an academy of medicine in $1973^{1} \mathrm{I}$ am stimulated to comment on your leading article on this subject (22-29 December, p 1611), which merits special attention and whose main theme I strongly support. Over the years I too have found that there is no generally recognised source of medical and allied opinion on many of the problems confronting the National Health Service.

While individual royal colleges are more numerous than before the second world war, in my view not all of these speak for a really narrow segment of medical opinion. For example, the Royal College of Physicians and Surgeons of Glasgow includes in its membership and fellowship a wide variety of hospital physicians and surgeons, including dental surgeons, pathologists, radiologists; and also general medical and dental practitioners working outwith hospitals.

E K BLACKBURN

Department of Haematology,

Hallamshire Hospita

1 Blackburn EK. Br Med f 1973;ii:181.

Tamoxifen-induced hypercalcaemia and response to treatment

SIR,-During the last 25 years it has been debated whether hormone-induced or exacerbated hypercalcaemia in women with advanced breast cancer and bone metastases is a predictive factor for response. The literature contains conflicting evidence and there have been suggestions that this phenomenon may precede a good response or, more commonly, a poor one to treatment with oestrogens, androgens, or progestogens. ${ }^{1-4}$

In the report by $\mathrm{Dr} \mathrm{A} \mathrm{H}$ Villalon and his colleagues (24 November, p 1329) concerning tamoxifen-induced hypercalcaemia four cases are reported. In only two cases was tamoxifen continued and in one of these it was in combination with chemotherapy. Thus only one patient (with an oestrogen-receptorpositive tumour) was assessable for response to tamoxifen alone. Moreover, all patients received prednisolone for an unspecified period and this steroid does occasionally produce sclerosis in bone metastases as shown by Stoll $^{5}$ and our own unpublished observations. Hence this report does not provide acceptable evidence that tamoxifen-induced hypercalcaemia predicts a tumour response to this agent. While we have seen one patient who had a remission following tamoxifeninduced hypercalcaemia, ${ }^{6}$ four other patients 